\title{
1 Environmental sustainable decision 2 making- the need and obstacles for 3 integration of LCA into decision analysis
}

4 Yan Dong ${ }^{a, b, *}$, Simona Miraglia ${ }^{a, c 1}$, Stefano Manzo ${ }^{a, d}$, Stylianos Georgiadis ${ }^{a, e}$, Hjalte Jomo Danielsen Sørup ${ }^{a, f}$, Elena Boriani $^{a, g}$, Tine Hald ${ }^{a, g}$, Sebastian Thöns ${ }^{a, c}$, Michael Z Hauschild ${ }^{a, b}$

a. Global Decision Support Initiative, Technical University of Denmark, DK-2800 Kgs. Lyngby, Denmark

b. Quantitative Sustainability Assessment, Department of Management Engineering, Technical University of Denmark, DK-2800 Kgs. Lyngby, Denmark

c. Structural Engineering, Department of Civil Engineering, Technical University of Denmark, DK-2800 Kgs. Lyngby, Denmark

d. Transport Modelling, Department of Management Engineering, Technical University of Denmark, DK-2800 Kgs. Lyngby, Denmark

e. Statistics and Data Analysis, Department of Applied Mathematics and Computer Science, Technical University of Denmark, DK-2800 Kgs. Lyngby, Denmark

f. Urban Water Systems, Department of Environmental Engineering, Technical University of Denmark, DK-2800 Kgs. Lyngby, Denmark

g. National Food Institute, Technical University of Denmark, DK-2800 Kgs. Lyngby, Denmark

* Corresponding Author. Tel: +45 4525 4417; E-mail: yado@dtu.dk

\section{Highlights}

- Extensive range of environmental impacts is rarely considered in decision analysis.

- LCA can provide sophisticated environmental profiles of decision alternatives.

- LCA and other decision analysis tools have different goals, principles and systems.

- Consistency of study system between LCA and other tools is the key for integration.

\section{Abstract}

Decision analysis is often used to help decision makers choose among alternatives, based on the expected utility associated to each alternative as function of its consequences and potential impacts. Environmental impacts are not always among the prioritized concerns of traditional decision making.

\footnotetext{
${ }^{1}$ Current address: Division of Reliability, Dynamics and Marine Engineering, Department of Civil Engineering, Aalborg University, Thomas Manns Vej 23, 9220 Aalborg Ø
} 
This has fostered the development of several environmental problems and is nowadays a reason of concern. Life Cycle Assessment (LCA) can assess an extensive range of environmental impacts associated with a product or service system and supports a life cycle perspective on the alternative products or service systems, revealing potential problem shifting between life cycle stages. Through the integration with traditional risk based decision analysis, LCA may thus facilitate a better informed decision process. In this study we explore how environmental impacts are taken into account in different fields of interest for decision makers to identify the need, potential and obstacles for integrating LCA into conventional approaches to decision problems. Three application areas are used as examples: transportation, flood management, and food production and consumption. The analysis of these cases shows that environmental impacts are considered only to a limited extent in traditional evaluation of transport and food projects. They are rarely, if at all, addressed in flood risk management. Hence, in each of the three cases studied, there is a clear need for the inclusion of a better and systematic assessment of environmental impacts. Some LCA studies have been conducted in all three research areas, mainly on infrastructure and production systems. The three cases show the potential of integrating LCA into existing decision analysis by providing the environmental profiles of the alternatives. However, due to different goals and scopes of LCA and other decision analysis approaches, there is a general lack of consistency in study system scoping in terms of considered elements and boundaries, in uncertainty treatment, and in applied metrics. In the present paper, we discuss the obstacles arising when trying to integrate LCA with conventional evaluation tools and we propose a research agenda to eventually make such integration feasible and consistent.

\section{Keywords}

Decision analysis, Life cycle assessment, Cost benefit analysis, Risk assessment, Decision support

\section{Introduction}

Decision support systems are often used to guide decision makers towards the best decision. Decision theory as mathematical basis of decision making under uncertainty was formulated in the $20^{\text {th }}$ century. Following a structured methodology, it aims at selecting one out of different available alternatives, based on the consequences associated to each alternative. Due to different context of application in several scientific disciplines, different approaches may be used in the specific field of application. Risk-based decision making, as one of the widely used approaches, has been used to address the concern for human, societal, economy and ecosystem health when exposed to unfavorable events, e.g. natural hazards, contamination etc. (Klüppelberg et al., 2014). Cost benefit analysis (CBA) is another approach, used to identify the alternative that can achieve a particular goal with lowest cost (Mishan and Quah, 2007). In parallel or in combination with CBA, Multi-criteria analysis (MCA) is often used to evaluate the alternatives based on a set of measurable criteria (Figueira et al., 2005). These approaches are broadly used in both public and private sectors with a particular aim: to help decision makers choose the most appropriate alternative to achieve their goals, according to a certain set of criteria.

Among these concerns and criteria, environmental problems are not well represented. This has caused tremendous problems in the past, examples being the London fog in last century and acid rains. The 
former one is a result of burning soft coal for heating, while the later one comes from the excessive emission of $\mathrm{SO}_{2}$ and $\mathrm{NO}_{x}$ mainly from the burning of fossil fuels. These phenomenon happen because there is not enough awareness of the potential damages, which leads to the lack of relevant control measures. These environmental problems could have been avoided if the life cycle perspective of environmental impacts associated with the energy product use are considered beforehand. To reduce the occurrence of similar events, many regulations and proposals have appeared afterwards (Kahn, 2007), acting towards precautionary purposes, with different environmental focus and decision analysis prospective in specific sectors. For example, noise problems have traditionally been considered in transportation decision analysis (European Commission, 2014). Pathogen and chemical impacts on human health have conventionally been taken into account in food safety decisions (FAO and WHO, 2005). Impacts on climate change have recently been considered in decision analysis for e.g. flood management, and transportation planning. Note that a wide range of environmental impacts may arise as a consequence of man-made activities (e.g. climate change, eutrophication, acidification, etc.). For the sectors mentioned above and the majority of other sectors, focus has been on a rather limited selection of environmental impact categories following regulations and proposals. Some attempts exist on accounting for a broader selection of environmental impact categories, via approaches such as MCA (Halsnæs et al., 2015; Munda, 2005). However, it is not common to see a decision analysis that covers an extensive set of environmental impacts for the alternatives, which can sometimes lead to controversial results. For example, when facing several alternatives in a transport project, the best alternative according to CBA may not have the best environmental performance, due to e.g. neglecting environmental impacts from the life span of vehicles and infrastructures (Chester and Horvath, 2009). Were these to be included through taking a life cycle perspective, the preferred alternative may turn out to cause more damages on ecosystems, and the cost for amending such damages may be more than the savings on the infrastructures. Without having proper environmental impact assessment in decision analysis, such information cannot be revealed and the decision making will be misguided. The lack of such practice may be ascribed to the lack of a common understanding of the needs and of the possible ways to integrate the relevant environmental impacts into existing decision analysis tools.

Many methods and tools were developed or adapted to assess environmental impacts, including e.g. Environmental Impact Assessment, Life Cycle Assessment (LCA), input-output analysis, etc. Zijp et al. (2017) summarized the methods available for assessing environmental sustainability and provides a model for the selection of suitable method corresponds to the decision context. LCA standards out for its inclusive of cradle to grave perspective, flexibly in spatial scale, and its feasibility of application during product development and commercial stages. With its life cycle-based systems perspective and broad coverage of environmental impacts, LCA is indeed a promising tool for assessing environmental sustainability (Sala et al., 2013). It quantifies resource use and environmental impacts that are associated with a product or service into an extensive set of impact categories (ECJRC, 2010). LCA is currently the most mature with its basic principles laid down in an international set of standards (ISO 14040/14044) (Kloepffer, 2008). It has been adopted by public sectors for e.g. prioritizing research in energy sector in USA (Bosso et al., 2012) and implementing sustainable strategies in EU (European Commission, 2016). Private sectors also use LCA frequently for choosing 
the environmentally friendly alternatives, materials and services and for communicating via environmental product declarations or ecolabels. However, LCA is not a legal requirement in any regulatory context (Bosso et al., 2012; European Commission, 2016). It has the potential to give a good overview of environmental impacts related to each decision alternative, to be taken into account in decisions.

Taking some specific research disciplines as example, the aim of this study is to: 1) explore how environmental impacts are taken into account in the current decision analysis approaches; 2) review the application of LCA in those fields and 3) explore the need, obstacles and potential for integrating LCA into decision analysis. First, decision analysis theory and LCA will be introduced. Then we will look into three specific research disciplines, namely flood management, transport projects and food production and consumption to address the aim of the study. These three research fields have high societal relevance, and there is a strong need for considering environmental perspectives in their decision analysis. They have different conventional decision analysis approaches that represent a variety of challenges for the integration of LCA.

\section{Decision analysis}

The ultimate goal of decision making is to select one out of different available alternatives, which most likely leads to the most favorable outcome. Due to the uncertainty, we cannot identify the optimal choice by means of deterministic values (Faber, 2008). Therefore, decision analysis aims at evaluating alternatives based on the changes that they operate on expected utility associated to the performance of system, i.e. the benefits and the consequences. This facilitates objective and informed decisions by enclosing the decision process into a structured methodology, giving a mathematical representation to the evaluation process aiming at identifying the most favorable outcome with respect to possible alternatives.

According to Keeney (1982), any decision problem can be structured following four main steps as shown in Figure 1. The first step - scope definition of the decision problem - is of key importance, because choices and assumptions made in this phase will influence the entire decision process. Therefore, it is important to get a clear definition of the decision problem, the expected improvement (objectives) from the Decision Maker (DM) and the identification of the feasible and affordable alternatives out of all possible ones. The scenario identification phase (phase two) includes forecasting of the impact of each alternative on the performance of the system (though modelling and/or data collection and analysis) and the uncertainty characterization, quantification and propagation. The third phase refers to the quantification of DM's preferences. Preferences represent how attractive, valuable, convenient and favourable the DM judges the alternatives to be with respect to their impact on the system (Raiffa and Schlaifer, 1961). This value trade-off and risk attitude of the DM is translated into an objective function (utility function) representing a weighted average of the utility associated to all possible outcomes (French and Rios Insua, 2000; Raiffa and Schlaifer, 1961). The optimal alternative will be the one maximizing the expected value of the utility function. Phase four, deals with the optimization of the utility function and sensitivity analysis to assure robustness and consistency of the solution. The four steps in Keeney (1982) represent, however, a 
very general decision problem paradigm. In real decision analyses, feedback loops and iterations are required as will also be shown in Figure 2.

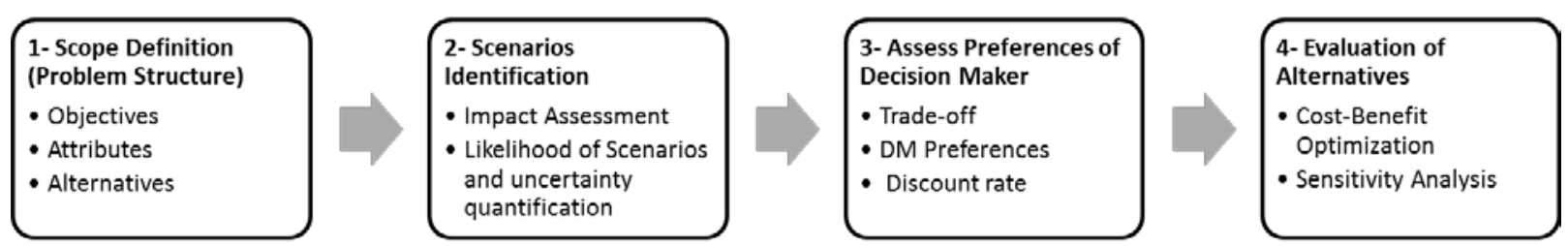

149

\section{Figure 1. Steps of the Decision Making Process, adapted from Keeney (1982)}

Uncertainty, which refers to the incompleteness of knowledge or the lack of understanding, affects largely the decision process. Variability, i.e. aleatory uncertainty, describes the inherent variations and randomness of the quantity, process or system of interest and it cannot be eliminated. Temporal, spatial or inter-object variations are some of the -not mutually exclusive- categories of variability. Epistemic uncertainty is caused by lack of knowledge and can be reduced e.g. by means of further measurement or study of the quantity, process or system. Where epistemic uncertainty and variability occur may vary, but two types are widely mentioned: model uncertainty and parameter uncertainty. Model uncertainty captures the imperfect representability of the true processes and systems. Parameter uncertainty refers to the lack of knowledge of the exact parameter value in a model. Other classifications and terminologies of uncertainty exist (e.g. Faber, 2012; Funtowicz and Ravertz, 1990; Kiureghian and Ditlevsen, 2009; Walker et al., 2003), that we do not further discuss in the paper. These include statistical uncertainty and scenario uncertainty, while errors, e.g. measurement and human errors, are often considered as uncertainty sources. Regardless of location and source, epistemic uncertainty and variability need to be properly treated throughout an analysis and communicated.

\subsection{Risk-based decision analysis}

Risk arises whenever there is uncertainty on potentially adverse events causing unfavourable consequences, within a specific time frame (JCSS, 2008). Risk-based decision making is a widely used tool to assess performance and evaluate policies for complex systems and services where potential risks exist. For instance, it is often applied to answer the decision problem such as choice of mitigation policies against natural disasters (earthquakes, floods etc.) and evaluation of food safety.

There are various definitions of risk, which may be defined as "combination of the consequences of an event (including changes in circumstances) and the associated likelihood of occurrence”, following ISO31000:2009. The evaluation of the risk can be formalized in different procedures according to the specific field of application. The ISO31000:2009 represents the general reference framework for risk management in industrial applications while ISO2394:2015 is the reference standard for both reliability and risk based decision making concerning design and assessment of structural systems. Figure 2 shows the two ISO standard frameworks, where ISO2394:2015 provides a more detailed description of the assessment procedure. The evaluation of risk analysis results, with respect to 
acceptance risk criteria defined by current regulations - e.g. Seveso III (European Union, 2012), REACH (EU, 2006), EUROCODE0-to-8 (CEN 1990:2002) etc.- or in some cases by engineering judgment, is an important phase in identifying the mitigation strategy based on the possible alternatives. Risk assessment can be conducted in a qualitative way, semi-quantitative or quantitative way. Uncertainty is widely analyzed in quantitative risk-based decision analysis (Bedford and Cooke, 2001; Klüppelberg et al., 2014) but less or not at all analyzed in qualitative and semi-quantitative risk assessment.

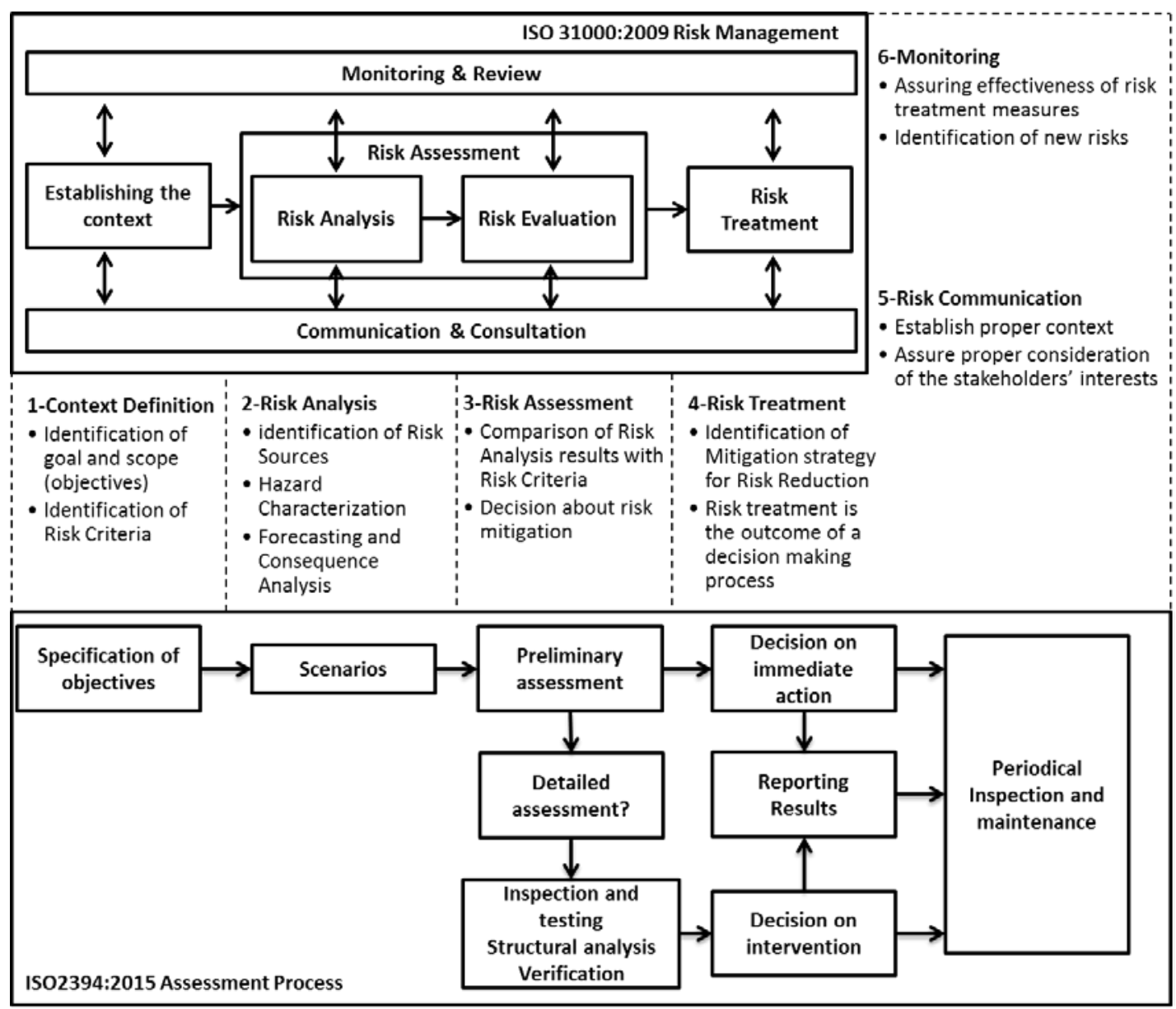

Figure 2. Parallel between Risk Management Framework adapted from ISO 31000:2009 and Assessment Framework adapted from ISO2394:2015

\subsection{Cost-benefit analysis}

Cost-benefit analysis (CBA) has been widely used to rank alternatives when the decision problem is structured in deterministic terms. CBA assumes that for each alternative, a specific consequence can be assigned in terms of cost and different benefits. In addition, we can assume that the measures of the different benefits are of such nature that they cannot be simply summed up and that the DM puts a limitation to the available budget to achieve a certain improvement. The best alternative will be the one whose cost does not exceed the available budget and whose benefits fulfil minimum "aspiration levels” (Keeney and Raiffa, 1993). By applying CBA, the benefits are converted into one metric using conversion factors, so that they can be summed up in one equivalent benefit. The alternatives are then 
ranked according to e.g. benefit-cost ratio and net present value. It is intuitive that CBA simplifies the evaluation of alternatives, especially considering that sometimes the conversion of the benefits into one measure can be very difficult to perform in rigorous terms. Additional limitations arise since both costs and benefits are often monetarized in CBA by deterministic values, where uncertainty of those values are not always available. CBA has been used in combination with risk management especially in flood management, where the probability distribution of the consequences associated with each alternative are identified by risk-based methods and the ranking of alternatives is conducted via CBA. However, CBA has also been applied in decision problems where no risk assessment is necessary such as improvement of the mobility of a region. Here the consequences are identified via a set of criteria assessed by mobility performance indicators, where CBA is applied for ranking. Discounting of costs and benefits over time is always applied in CBA, to actualize the future monetarized value of costs and benefits.

\subsection{Life Cycle Assessment}

LCA is applied in various cases to: 1) identify the environmental hotspots in the studied system or/and 2) compare the environmental impacts of different alternatives that can be applied in the studied system to achieve the same function. The system is analyzed over the whole life cycle of "goods or services ("products”)” (EC-JRC, 2010). According to ISO 14040 and 14044, there are four phases to conduct an LCA (Figure 3). The first phase formulates the question to be answered and defines the studied system. It first identifies the function to be provided by the product or service and describes it quantitatively and qualitatively in the form of functional unit, e.g. transport a certain number of people from one location to another over a certain number of years. Afterwards relevant elements that are needed to fulfill the functional unit is defined, e.g. two buses with capacity of 50 people. In the next phase, all relevant input and output in the form of resource consumption and emissions associated with the system's delivery of the functional unit are quantified in an inventory. Here the data is collected for all life stages of the product or service, i.e. raw material, manufacturing, use and end-of-life stages. In the third phase, the environmental impacts caused by the flows listed in the inventory are quantified. For each flow in the inventory, there is a cause-effect chain that describes the relationship between the flow and the damages on an area of protection (natural environment, human health or resources). Depending on the location of indicators in the cause-effect chain, the impacts can be characterized either at midpoint level with relevant indicators and metrics (e.g. kg $\mathrm{CO}_{2}$ equivalent for climate change, $\mathrm{kg} \mathrm{SO}$ equivalent for acidification, $\mathrm{kg} \mathrm{CFC}-11$ equivalent for ozone depletion, $\mathrm{kg} \mathrm{P}$ or $\mathrm{N}$ equivalent for eutrophication, $\mathrm{kg}$ NMVOC for photochemical oxidant formation, etc.), or at endpoint level (i.e. human health damages described in disability-adjusted life years (DALY), ecotoxicity damage described in Potential Disappeared Fraction of natural species in the ecosystem (PDF) or resource depletion described in monetary terms) (Hauschild et al., 2013). It's also possible to integrate the result into one single score, using weighting factors. In the fourth and final phase the outcomes are interpreted to answer the question that was posed in the goal definition, i.e. which product performs better or where is the hotspot? The interpretation can be performed either on the midpoint scores, endpoint scores, or on the single score, depending on the goal and stakeholder's preference. 


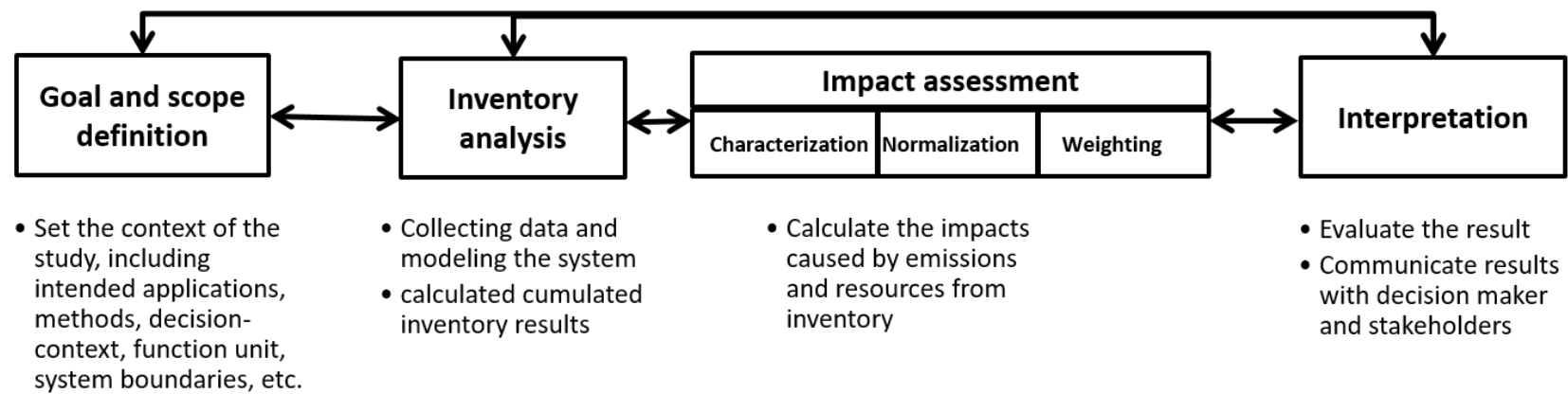

Figure 3. Steps of LCA, adapted from ISO 14040:2006.

Note that in addition to the conventional environmental LCA, social LCA (sLCA) and life cycle costing (LCC) also exist. They share the same principle as the conventional LCA, but looking at social impacts and cost flows respectively. Norris et al. (2001) proposed to use LCC for accounting economical cost and discussed two approaches for combining LCA and LCC for providing sustainability decision support. Hoogmartens et al. (2014) argue that LCA, sLCA and LCC together, the so-called life cycle sustainability assessment (LCSA), can well deliver a sustainability decision support. So far, sLCA, LCC and LCSA are used to a lesser extent due to the less mature methodology.

Uncertainty in LCA is addressed primarily on the input parameters by the practitioners, whereas the uncertainty on the impact assessment and model itself is rarely considered in current LCA practice, but mainly confined to academic applications (e.g. van Zelm and Huijbregts, 2013).

\subsection{Summary}

Decision analysis allows to rank available alternatives based on their consequences (e.g. in terms of human health impacts and economic benefit/loss), where environmental impacts are barely considered. LCA has the potential to fill this gap. It can be applied to analyze the environmental impacts associated with each alternative allowing their consideration together with the other conventional consequences for optimization. To identify the status and challenges involved in such combination, we look at application in three different research areas in the following sections.

\section{Decision analysis in three research fields}

In this section, we look into three research domains, namely flood management, transport and food production and consumption. We discuss and propose possible directions for integrating LCA-based environmental impacts into existing approaches used for decision support.

\subsection{Decision analysis in flood management}

Flood management is a fundamental societal service as it greatly increases the space where society can evolve and flourish. Protecting society is really protecting people and their assets from natural extremes, and since natural processes cannot be prevented, what is done is flood risk management rather than managing the floods; i.e. making sure that the risk of flood is acceptable from a societal point of view. 
The frequently asked questions by the decision makers are "which technical solutions" will provide "which degree of protection" and "at what cost". To answer these questions, traditionally risk assessment in combination with CBA is used as the decision analysis tool. In practice, risk assessment is translated into risk (cost) curves as illustrated by Zhou et al. (2012) and Halsnæs et al. (2015). Here the probability of scenarios are equal to the rarity of the natural phenomena causing the floods. The consequence is a complex product based on GIS analysis of which assets are actually affected by the flood and to what degree. Besides this, potential health issues stemming from the investigated flood problems are also considered in the consequences (as in e.g. Halsnæs et al., 2015). After an evaluation of the consequences in terms of monetary cost/benefit, CBA can be made and an optimal state where the risk (cost) of flooding is balanced against the cost of the technical solutions set in place to protect assets against flooding. Flood risk management is normally done on water catchment scale, either locally or regionally, depending on the natural of the risk in a given catchment. Uncertainty exists on input parameters of the consequence modelling, e.g. the variability of flood hazard occurrence rate and the "range of climate change risk estimates", and costing (Halsnæs et al., 2015). Those parameter uncertainties are often quantified, but the underlying model uncertainty is rarely treated explicitly.

Even though risk assessment in combination with CBA is a mainstream decision analysis tool in flood management, it is generally agreed that in its most widely used form, it excludes important relevant aspects in decision making if they are difficult to monetarize (Merz et al., 2014). Or the conclusions are made mainly dependent on the chosen prizing of the non-structural values (e.g amenity and health) (Halsnæs et al., 2015; Zhou et al., 2012). Thus, MCA is sometimes used instead of CBA to include consequences at different levels, including e.g. technical, hydraulic, environmental, sociological, economic, planning, operation and maintenance aspects (Martin et al., 2007), sustainability (Lai et al., 2008), and non-stationarity, i.e. and when in time to optimally invest in protection for systems undergoing climate change (Åström et al., 2014).

\section{How are environmental aspects considered?}

As stated in the EU flood risk management directive, “ It is feasible and desirable to reduce the risks of adverse consequences, especially for human health and life, the environment, cultural heritage, economic activity and infrastructure associated with floods” (European Commission, 2007). This clearly indicate that environmental impacts are desirable, but not mandatory to be included in flood risk management. As a consequence, it has "rarely been included in cost assessments up to now" (Meyer et al., 2013). Some studies have made the effort. For example, health costs was accounted in the case of Odense urban flooding management (Halsnæs et al., 2015). Another example is the inclusion of "greening" of cities in urban water management, such as green roof and green areas, is considered as the main sustainable measures (Belmeziti et al., 2015; Zhou et al., 2012). Nevertheless, methods have been tested to assess environmental impacts of infrastructure systems, mainly using LCA-based methods. But unfortunately only on cases that have come out of existing flood risk practice for further qualification of decision (e.g. Brudler et al., 2016), and not as input to decision regarding acceptable flood risk. 
When facing several alternatives for urban water management strategies (e.g. "green” or "grey" infrastructure), LCA is a good tool for accounting resource consumption and environmental impacts for the whole life cycle of the strategy as demonstrated by Brudler et al. (2016), De Sousa et al. (2012) and Spatari et al. (2011). LCA has also been conducted on smaller scales of infrastructure, e.g. stormwater treatment devices (Andrew and Vesely, 2008) and bio-infiltration rain gardens (Flynn and Traver, 2013). The results indicate that sometimes the apparent "green" strategy does not necessarily perform better in environmental impacts (De Sousa et al., 2012). Hence, it introduced important insight into the environmental impacts and it is worthwhile to integrate LCA into the current decision analysis for flood management. The provided environmental profile of the alternatives may have an impact on the stakeholder's decision. To achieve this, a possible approach is to assess the environmental impacts of each alternative and monetarize it as one cost/benefit in the traditional CBA, which will be further discussed in section 4 .

\subsection{Decision analysis in transport projects}

320 The primary aim of transport projects is to improve the mobility of persons and goods, often on local or regional level. This aim can be achieved in different ways, such as building a new infrastructure to increase the access to a specific location or providing a new public transport service. However, often several alternatives are at hand and a decision has to be taken in order to decide which one to implement. Traditionally, the decision analysis for transport projects is based on CBA. It facilitates the decision makers to choose the preferred alternatives based on a number of socio-economic budgets. In transport CBA some of the key variables are the output of transport demand models, such as travel time savings and vehicle kilometers travelled, while others are derived from such output, like number of accidents, noise and emissions, the so called "external costs". A challenge is to address the uncertainty inherent in the variables included in CBA and how it propagates to the final results. This issue has not been included in the standard CBA for transport until recently, although literature reports on investigations of how to quantify parameter uncertainty in both transport models (de Jong et al., 2007; Rasouli and Timmermans, 2012) and CBA (Fagnant and Kockelman, 2012; Salling and Leleur, 2015). In this respect, uncertainty in transport projects is commonly treated through stochastic simulations techniques such as Monte Carlo Simulation, and scenario analysis, in both scientific literature (de Jong et al., 2007) and practice (European Commission, 2014).

336 Transport CBA is usually complemented by other evaluation methods to cover more impacts. 337 Particularly relevant is the assessment of the so called wider economic impacts of the (transport) project, such as the agglomeration impacts and the effects on the labor market (Eddington, 2006), although some criticism has been raised with respect to the possibility of including them as part of standard transport evaluation frameworks (Gibbons and Overman, 2009). Besides, traditional CBA is sometimes replaced, combined or conducted in parallel with MCA. Nevertheless, some impacts remain difficult, if at all possible, to quantify through standard transport decision support methods, such as long term environmental impacts (Engelbrecht, 2009).

\section{How are environmental aspects considered?}


With respect to the appraisal of the environmental impacts deriving from transport projects, as mentioned in the above paragraph, the assessment of some of the environmental costs, such as air pollution and noise from vehicle operation, are normally included in standard CBA frameworks, following the EU guideline on CBA (European Commission, 2014). To calculate the costs related to noise and air pollution a bottom-up approach is commonly used. First, the amount of noise and pollution is quantified based on the estimated volumes of traffic, expressed in terms of vehicle kilometers (passenger vehicles) or ton kilometers (freight vehicles) travelled. Then, the estimated quantities are translated into monetary terms, based on available values from national and international guidelines.

However, some environmental costs related to the entire life-span of the project, such as the resource use, and some impacts on ecosystem and human health, are not covered. In addition, impacts associated with vehicles and infrastructures manufacturing and maintenance are usually not considered either. For instance, the Danish CBA guidelines (Danish Ministry of Transport, 2015) requires the inclusion in transport $\mathrm{CBA}$ of the monetary impacts of $\mathrm{CO}_{2}, \mathrm{NO}_{\mathrm{x}}, \mathrm{HC}, \mathrm{CO}, \mathrm{PM}_{2.5}$ and $\mathrm{SO}_{2}$ deriving from vehicles emissions but not from e.g. the construction of the infrastructure or the maintenance of the vehicles. Consistently, transport CBA projects only addresses vehicles emissions as reviewed by Annema et al. (2017).

In order to include the project life-span environmental costs into quantitative decision analysis for transport projects, some studies have applied LCA in evaluations. The existing literature can broadly be divided in two topic areas. The first, identifies the missing elements in the environmental impacts embedded in current decision analysis (Chester and Horvath, 2009) and points to hotspots where environmental improvement can be made, e.g. passengers and household behavior (Chester et al., 2010; Kimball et al., 2013). The second research area focuses instead on using LCA to quantify the environmental impacts of single elements in transport system, such as railway infrastructure (Linneberg et al., 2014), bridges (Hammervold et al., 2013), vehicles driven by different fuels or electricity (Bohnes et al., 2017; Garcia and Freire, 2017; Lombardi et al., 2017) and different mobility modes such as public bus and trucks (Ercan et al., 2015; Sen et al., 2017).

Despite the proven importance and possibility of assessing a broader range of environmental impacts, LCA is commonly not included within standard transport projects assessment frameworks. A feasible way for integrating LCA into current decision analysis for transport might be to monetarize environmental impacts assessed in the LCA, catering to their inclusion into standard CBA. Manzo and Salling (2016) practiced the proposal. The result shows that the inclusion of environmental impacts assessed by LCA indeed affecting the final project evaluation, while modifying the contribution from different components in the system. However, a better guideline for practice is needed for a better integration, which will be further discussed in section 4 .

\subsection{Decision support in food production and consumption}

The decisions made within the food production and consumption are largely aimed at assuring food safety and food security: prevent foodborne illness and guarantee its availability and good quality for the whole population. For this purpose, risk management (also called food safety risk analysis) is the 
most common used decision analysis tool in the field as illustrated in Section 2. A hazard in this context is defined as "a biological, chemical, or physical agent in or property of food that may have an adverse health effect” (WHO, 1995). After identifying the potential hazards, a full profile of the associated adverse effects on health is characterized, quantitatively or qualitatively. Exposure assessment is applied to find the amount and likelihood of intake. Which is then applied in a doseresponse relationship to estimate the risk of disease, i.e. the probability and severity of health effects that is caused by the hazard investigated (FAO and WHO, 2005). Food risk management can be operated on all geographical scales, including local, regional and global.

There are two major types of food risk assessment, according to the hazard property: microbial and chemical risk assessments. The major challenge for microbial risk assessment is to estimate the ingested dose, which is often done using stochastic modelling. Uncertainty on our knowledge of e.g. foods items contamination, pathogen survival and growth in the food product, and the probability of disease given a certain dose are often taken into account. The focus of chemical risk assessment is on the presence of potential harmful chemicals in the food (FAO and WHO, 2005). The allowed dose for a certain substance is often derived from animal testing, or calculated using models. The dose level where no adverse effects are observed is then divided by uncertainty factors (or safety factors) to ensure their safe application on human beings. These uncertainty factors are applied to account for interspecies and intraspecies variability. They are intended to assure adequate safety of the final toxicological value but may actually result in overly conservative safe dose estimates. The uncertainty mentioned above focus on parameter uncertainty, which is usually treated in studies. In contrast, model uncertainty is rarely quantified.

In addition to the traditional risk assessment mentioned above, CBA is sometimes also used for food decision making. Some food such as fish and nuts has positive benefits on human health, but they can also contain harmful substances, e.g. heavy metals and carcinogenic toxins. The negative risks are sometimes compared with the positive benefits of food to help determine whether the food has an overall health benefit (EFSA, 2006).

\section{How are environmental impacts considered?}

In terms of food security, there is a strong need for a more sustainable food production and consumption to be able to feed the predicted global population of 9.5 billion people by 2050, with respect of less environmental impacts and resource depletion. UNEP presented several long term targets and indicators for "sustainable agriculture and food security" (UNEP, 2014), e.g. reducing food and nutrient loss along production and consumption. Van der Goot et al. (2016) concluded that current food production manners are not very efficient, where the losses of food are significant along the production chain. Research and application of technology development and new farming systems are promoted by European Commission to enhance sustainability in food production (Freibauer et al., 2011). These sources point to the fact that currently there is an increasing attention to reduce environmental impacts in food production and consumption. This is also reflected in the EU regulations such as food law (European Commission, 2002) that "the protection of animal health and welfare, plant health and the environment” should be pursued in food regulations. But still a 
harmonized system and operation procedure is missing to implement environmental considerations in decision making along the whole food production chain from primary production to consumption. LCA has been extensively conducted for the production and processing of industrial food products, dairy and meat production, fruits, and agricultural products. As summarized in Arvanitoyannis et al. (2014) and Roy et al. (2009), these studies mainly aim at 1) identifying hotspots in the system for future improvement, and 2) comparing different food and their related products (e.g. packaging), to identify the best choice regarding environmental impacts. These LCA studies shows a strong potential of solving food security problem in the cause of less environmental impacts.

Food production is an important source of many environmental impacts and there are potential tradeoffs between food risk minimization and sustainability of the alternatives in food production system. However, environmental sustainability aspects are rarely taken into account. It will thus be beneficial to integrate LCA into the current food risk management practice to quantitatively assess environmental impacts associated with the alternatives that minimizes the risks. There are some common metrics (e.g. DALY) that are used to present results both in LCA and food safety risk assessment, which may potentially serve as the basis for the integration of LCA and risk assessment for food safety as shown in Stylianou et al., (2016). Note that DALY only describes human health consequences, whereas animal health and welfare, and impacts on ecosystems cannot be expressed. For those aspects, research is needed to convert LCA output in a valuable metric for food safety risk assessment.

\section{Discussion on the need, obstacles and research agenda for integrating LCA into decision analysis}

We have screened the major criteria considered in the current decision analysis of three application areas. It turns out that economical costs and benefits are the major concerns in transport and flood management, where CBA is often used to prioritize alternatives in decision analysis. Human health is the focus in food safety related decisions, where traditional risk management is often used to prioritize alternatives. Environmental benefit/cost is rarely considered in flood management, and to a very limited extent in transport projects, focusing on few pollutants in few life stages. In food safety related decisions, though human health caused by the food itself is well taken into account, the environmental impacts arising from the rest of the food system, are not considered and these also have the potential to impact negatively on human health e.g. through climate change or release of toxicants that expose humans through the environment. Comprehensive environmental considerations are not well addressed in decision analysis tools, making them inapt to support decisions towards sustainability.

LCA offers a solution to the problem. It has been applied in transport and flood management to assess the environmental impacts arising from infrastructures and resource consumptions. LCA also has the potential to quantify the environmental performance of food risk mitigation actions. Such results can provide valuable information to support decisions if combined with the main decision analysis tool such as CBA or risk assessment. A summary of the main elements in decision analysis for the three research areas covered in this study and LCA is presented in Table 1. It can be clearly seen that there 
are many discrepancies between the conventional decision analysis and LCA. First of all the goal is different. While LCA aims at assessing environmental impacts, the conventional decision analysis tries to solve decision problem such as how to protect human beings and properties from certain risks, and how to provide a service to satisfy human being's basic needs. This results in the different choice of principles, i.e. non-precautionary, precautionary and cautionary principle. The covered impacts, study system and uncertainty treatments also vary between different methods.

These discrepancies are confirmed by other references. Cowell et al. (2002) discussed the application of risk assessment and LCA in regulatory context. They found that, similar to the situation in flood management and food risk assessment in this study, risk assessment works with a precautionary principle, where both absolute and comparative results can be delivered. LCA, in contrast, aims at quantifying the average or marginal consequences, and only comparative results are expected. In analogy to the transport project, Hoogmartens et al. (2014) highlights that CBA has been mainly applied for policy or strategic decision making, where the project is the main focus, meaning that the time span and system boundaries are defined by the project. CBA puts emphasis on the socioeconomic impacts rather than external environmental impacts. In contrast, conventional LCA is product oriented, which results in the different system boundaries, and it focuses on environmental impacts rather than social and economic impacts. In recent years, LCA has been used in a broader scope, such as assessing impacts for services (Barjoveanu et al., 2014), urban metabolism (Goldstein et al., 2013), and larger scale applications (Lotteau et al., 2015) and territorial planning (Loiseau et al., 2018). Correspondingly, the term of "product" has been extended from a single product to services, sectors, cities, etc. Still, the focus is on the function provided by the service, product or system, which is different from CBA and risk assessment. By integrating two different methods together to solve the same decision problem, those discrepancies bring us the opportunities to obtain a more comprehensive picture of the potential consequences of the decision. But the methods and results also need to be integrated in a transparent and coherent way to avoid inconsistency among options under comparison. Main discrepancies from our three application areas are discussed in the following section, concluding with a proposed future research agenda.

\subsection{Compatible study system}

A clear identification of the boundaries and temporal scope of the system under assessment is necessary, such that the system is identical for both LCA and the other traditional decision analysis approaches. System boundaries are not always easy to identify. In CBA and risk assessment, the system is defined by the project or hazard prone area, meaning that only elements and associated life stages relevant for the life cycle of the system are included (i.e. both spatial and temporal boundaries). In contrast, the system boundary defined in LCA as function to be provided (function unit), within all life stages of the system (i.e. both temporal and spatial boundaries). This leads to difficulties in identifying a consistent system boundary when the results delivered by two methods need to be combined into a common decision pathway. Whereas incompatibility of boundaries is not avoidable, it is on a case-by-case discussion whether that incompatibility has a large influence on the results. And it needs to be transparently presented to the audience so that they are aware of the differences. For example, in flood management and transport projects, an infrastructure is a mean to improve mobility or to prevent floods. According to the specific goal and scope of the analysis, the 
infrastructure may provide more than one function from the perspective of CBA, risk assessment and LCA. For instance, a dike may be built with a road on the top. This provides extra mobility function in addition to its primary function, i.e. storm water management. If those two alternatives are for comparison, one dike with road and one without, and the scope of the project is only storm water protection with system boundaries limited to the dike itself, then the two alternatives are equivalent in the prospective of conventional flood management. However, they are still different in LCA, since one alternative provides an extra mobility function, which needs to be accounted for and compared to a matching infrastructure providing the same mobility function within the system boundary. Allocating the proper share of environmental impacts to the main function can potentially align the system boundary with CBA, where caution is needed for the alignment. Another concern is which life stages to include in the system when considering that some of the environmental impacts occurring along the life cycle do not affect the project location, e.g. the emissions for construction material production may not happen in the same place where the infrastructure is built and used. From the perspective of LCA, all emissions regardless of location should be included. In contrast, CBA of an infrastructure may only take into account the emissions that happens within its concerned local geographical scope as a valid environmental cost (EIB, 2013; European Commission, 2014). This emphasizes that the geographical coverage needs to be clearly identified during the project assessment and communicated to the decision process.

Temporal scope is another issue that needs to be addressed. Decision analysis is always dealing with time. Benefits and costs are discounted over years in e.g. transport projects and flood management in standard methods. But when it comes to impacts on human health, discounting is not always conducted due to ethical issues (Motarjemi et al., 2014). LCA calculates impacts from Life Cycle Inventory (LCI) flows representing the aggregated load of emissions over the life cycle of a product or service. The traditional LCA thus only provides time-integrated results over the product. Recently, studies have explored dynamic LCA, considering that emissions in reality often happen over a period of time (Levasseur et al., 2010). However, applying discounting across generations on environmental impacts in LCA is not encouraged, due to ethical concerns similar to the ones applying to the human health impacts (Hellweg, 2003). There is no single answer to whether LCA results should be discounted when they are being integrated with other decision analysis tools. It depends on the impact category and the decision context. However, as a rule of thumb, it is essential to have consistency in discounting when aggregating similar impacts in LCA and other decision analysis tools.

\subsection{Cautionary principle vs. non-cautionary principle}

"Cautionary principle means that caution, for example by not starting an activity or by implementing measures to reduce risks and uncertainties, shall be the overriding principle when there is uncertainty linked to the consequences" (Aven, 2008). In the extreme case where scientific uncertainty of the consequence is lacking, e.g. flooding due to climate change, it can be referred as precautionary principle (Aven, 2008). The cautionary principle is applied in many contexts, especially where riskbased decision approaches are applied. Thresholds are one way to apply a cautionary principle, e.g. there are thresholds for many chemicals that cannot be exceeded in food products. In EU food policies, those thresholds are even set up according to precautionary principle that supports taking protective action before a complete scientific proof of a risk, e.g. prohibition of the use of growth hormones in 
544 beef production. Similarly, cautionary requirements exist for infrastructures, where a certain level of 545 safety against natural disaster, such as flood and earthquakes, needs to be achieved. In those cases, 546 the cautionary and precautionary thresholds and requirements will limit the number of alternatives 547 available for optimization in decision analysis. In contrast, LCA aims at comparing environmental 548 burdens with "best estimate of risk on the basis of scarce knowledge" (Hauschild, 2005). The 549 cautionary constrains are not applied in LCA, which does not limit the applicability of alternatives 550 via thresholds and requirements as in the cautionary principle based tools. Recently developed 551 methods aiming at translating LCA results into limited carrying capacity may help harmonize this 552 discrepancy (Bjørn and Hauschild, 2015). 
554 Table 1. Summary of main elements in decision analysis and LCA for the three research areas in this study

\begin{tabular}{|c|c|c|c|c|c|}
\hline & & \multicolumn{3}{|c|}{ Conventional decision analysis } & \multirow{2}{*}{ Life Cycle Assessment } \\
\hline & & $\begin{array}{l}\text { Flood management } \\
\text { decision analysis }\end{array}$ & $\begin{array}{l}\text { Transport project } \\
\text { decision analysis }\end{array}$ & $\begin{array}{l}\text { Food production and } \\
\text { consumption decision } \\
\text { analysis }\end{array}$ & \\
\hline \multicolumn{2}{|c|}{ Main method } & $\begin{array}{l}\text { Risk assessment in } \\
\text { combination with } \\
\text { CBA }\end{array}$ & $\begin{array}{l}\text { CBA (often combined } \\
\text { with MCA) }\end{array}$ & Risk assessment & $\begin{array}{l}\text { Life cycle inventory quantification and } \\
\text { life cycle impact assessment }\end{array}$ \\
\hline \multirow[t]{2}{*}{$\begin{array}{l}\text { Studied } \\
\text { system }\end{array}$} & $\begin{array}{l}\text { System } \\
\text { components }\end{array}$ & $\begin{array}{l}\text { People and assets } \\
\text { within the urban } \\
\text { environment (e.g. } \\
\text { buildings, roads, } \\
\text { water } \\
\text { infrastructure). }\end{array}$ & 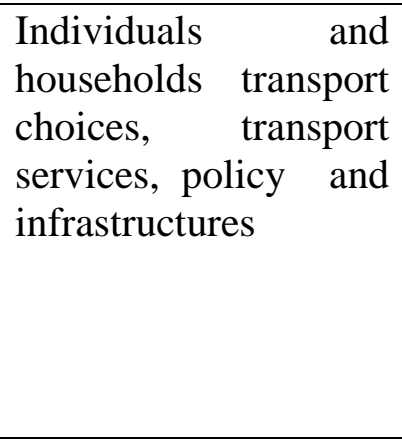 & $\begin{array}{lr}\text { Agriculture } & \text { farming, } \\
\text { food } & \text { production } \\
\text { system, rood } \\
\text { consumption and waste } \\
\text { treatment }\end{array}$ & $\begin{array}{l}\text { For flood: Infrastructure of urban water } \\
\text { management system } \\
\text { For transport projects: Infrastructure of } \\
\text { transportation system, vehicles driven } \\
\text { by different fuels and mobility modes } \\
\text { For food production and consumption: } \\
\text { Farming process, food production } \\
\text { system, consumption and waste } \\
\text { management }\end{array}$ \\
\hline & $\begin{array}{l}\text { System } \\
\text { boundary }\end{array}$ & $\begin{array}{l}\text { All relevant } \\
\text { elements within } \\
\text { the utility function; } \\
\text { including: } \\
\text { identified risks, } \\
\text { actions to be taken, } \\
\text { investment, costs } \\
\text { of consequences, } \\
\text { etc. }\end{array}$ & $\begin{array}{l}\text { Costs and benefits } \\
\text { foreseen from the } \\
\text { project expressed in } \\
\text { monetary terms }\end{array}$ & $\begin{array}{l}\text { All relevant elements } \\
\text { within the utility } \\
\text { function, including } \\
\text { identified risks, actions } \\
\text { to be taken, investment } \\
\text { and costs, etc. }\end{array}$ & $\begin{array}{l}\text { All flows related to delivering the } \\
\text { functional unit, including raw } \\
\text { materials, production, consumption/ } \\
\text { maintenance and waste management }\end{array}$ \\
\hline \multirow[t]{2}{*}{$\begin{array}{l}\text { Goal and } \\
\text { Scope }\end{array}$} & General goal & $\begin{array}{l}\text { Protect people and } \\
\text { assets from flood. } \\
\text { Control the risk of } \\
\text { flood to an } \\
\text { acceptable level }\end{array}$ & $\begin{array}{l}\text { To guarantee and } \\
\text { enhance the mobility } \\
\text { of persons and goods }\end{array}$ & $\begin{array}{l}\text { Guarantee food safety } \\
\text { and availability }\end{array}$ & $\begin{array}{l}\text { Assess impacts on ecosystem and } \\
\text { human health on comparative bases }\end{array}$ \\
\hline & Scale & $\begin{array}{l}\text { Water catchment } \\
\text { (Local/Regional, }\end{array}$ & Local or regional & $\begin{array}{l}\text { Local, regional and } \\
\text { global }\end{array}$ & $\begin{array}{l}\text { Impacts caused by the studied system } \\
\text { are assess in a comprehensive way, }\end{array}$ \\
\hline
\end{tabular}




\begin{tabular}{|c|c|c|c|c|c|}
\hline & & $\begin{array}{lr}\text { usually } & \text { following } \\
\text { natural } & \text { water } \\
\text { divides) } & \end{array}$ & & & $\begin{array}{l}\text { Depends on the impact category, the } \\
\text { scale of consequences can be global } \\
\text { (such as climate change) or local (such } \\
\text { as eutrophication) }\end{array}$ \\
\hline & $\begin{array}{l}\text { Cautionary } \\
\text { or non- } \\
\text { cautionary }\end{array}$ & Precautionary & $\begin{array}{l}\text { Cautionary in most } \\
\text { cases }\end{array}$ & $\begin{array}{l}\begin{array}{l}\text { Precautionary and } \\
\text { cautionary }\end{array} \\
\end{array}$ & Non-cautionary \\
\hline \multicolumn{2}{|c|}{ Covered impacts } & $\begin{array}{l}\text { Economic } \\
\text { benefit/loss }\end{array}$ & \begin{tabular}{|l|} 
Socio-economic \\
benefits/cost; \\
environmental \\
impacts to a much less \\
degree
\end{tabular} & $\begin{array}{l}\text { Human health; impacts } \\
\text { on ecosystem to a less } \\
\text { degree }\end{array}$ & $\begin{array}{l}\text { Environmental impacts, human health } \\
\text { impacts and resource impacts }\end{array}$ \\
\hline \multicolumn{2}{|c|}{ Location and time } & \multicolumn{3}{|c|}{ The consequences are time and location dependent } & $\begin{array}{l}\text { The consequences are integrated over } \\
\text { time and location is unspecific }\end{array}$ \\
\hline \multirow[t]{2}{*}{$\begin{array}{l}\text { Uncertain } \\
\text { ty }\end{array}$} & $\begin{array}{l}\text { Parameter } \\
\text { uncertainty }\end{array}$ & Usually treated & Usually treated & Usually treated & Occasionally treated \\
\hline & $\begin{array}{l}\text { Model } \\
\text { uncertainty }\end{array}$ & Rarely treated & $\begin{array}{l}\text { Rarely treated, but } \\
\text { recommended } \\
\text { guidelines }\end{array}$ & Rarely treated & $\begin{array}{l}\text { Rarely treated, but recommended by } \\
\text { guidelines }\end{array}$ \\
\hline
\end{tabular}




\subsection{Uncertainties}

The reliability of the decision analysis results can only be assessed through an evaluation of the uncertainty. As mentioned in section 2, parameter and model uncertainty are the two essential forms of epistemic uncertainty and variability in an analysis. The usual approach for dealing with the parameter uncertainty is to assign a probability distribution to each input parameter, fitting the best to data. In LCA, only four types of distributions are normally used due to software limitations and the complexity of the modelled product life cycle: normal, lognormal, uniform and triangular distributions (Heijungs and Frischknecht, 2005). In the decision analysis approaches applied in flood, transport and food, more distribution patterns are applied, e.g. Gamma, Beta, Weibull and Generalized Extreme Value distributions (Faber, 2012). Generally, distribution patterns are fitted to data in the other decision analysis approaches, but not often in LCA. Compared to parameter uncertainty, model uncertainty is given much less attention by practitioners, both in LCA and decision analysis within the three discussed research areas, and often it is completely neglected.

Monte Carlo and other simulation methods are the primary approach to propagate the uncertainty to the output in the decision analysis for all three considered research areas and LCA, assuming different distribution patterns of chosen input parameter (de Jong et al., 2007; Halsnæs et al., 2015; Lloyd and Ries, 2007; Vose, 1998). An important feature of LCA is that it provides impacts on a site-generic and time-integrated scale. Thus, spatial and temporal variations are not often represented in the result. In the recent years efforts have been made to develop spatial differentiated LCA methods (Huijbregts et al., 2015; Wernet et al., 2016). However, due to the diverse location of elements included in the system, data availability, and the diverse location of impacts, it is not easy to reach a systematically regionalized LCA result. On the contrary, risk-based methods and CBA provide full uncertainty quantification in time and space. These aspects need to be harmonized in the problem definition when integrating LCA with other decision analysis approaches.

\subsection{Combining LCA and other decision analysis tools - current status and recommendations}

There are some studies discussing the similarity and difference between LCA and risk assessment. Olsen et al. (2001) concluded that LCA and risk assessment are not substitutable due to different aims, scopes, etc. Bare (2006), Flemström et al. (2004) and Cowell and Clift (2000) reached similar conclusions after comparing LCA and risk assessment within the context of human health impact, chemical toxicity and public decision making respectively. Despite the difficulties, a few studies have still attempted to combine LCA with risk assessment for a better decision support. Linkov et al. (2017) summarized that two mainstream methods exist for such integration. One is to apply risk assessment on different life stages where risky materials appear. The other one is to apply risk exposure pathway and impact in LCA methodologies in some impact categories, such as the method proposed by OECD (2015) for nano-enabled applications. Harder et al. (2015) reviewed case studies blending risk assessment and LCA. They conclude that in addition to the two methods mentioned above, LCA and risk assessment in many cases studies were conducted in parallel to complement each other. However, none of them can really deliver results integrating the environmental impacts and risk consequences (e.g. Barberio et al., 2014; Dhingra et al., 2010; Ribera et al., 2014). Guinée et al. (2017) points out that tools such as multi-criteria decision-making is emerging in the past decade to deliver a full combination of LCA and risk assessment result (e.g. Benetto et al., 2007; Linkov and Seager, 2011; 
Tsang et al., 2014). Normalization or weighting may be performed to allow the harmonization of assessment results from LCA and risk assessment depending on the stakeholders' preference, where the results can be combined together. These studies show that though obstacles exist, efforts has been made to integrating LCA with risk assessment, that may serve as inspiration e.g. for flood and food decision analysis when risk assessment is the main tool.

The combination of LCA and CBA has also been conducted in few studies. Møller et al. (2013) used LCA to quantify energy consumption and $\mathrm{CO}_{2}$ of biofuel production. There "welfare economic accounting prices" were assigned to those results and integrated into traditional CBA for comparing the consequences of using three different biofuels in Denmark. In Jones et al. (2017), $\mathrm{CO}_{2}, \mathrm{SO}_{2}$, $\mathrm{PM}_{10}$, NMVOC and N emissions were quantified over the life cycle of a transport service provided by train, which are further monetized and integrated into CBA to calculate NPV. Huang et al. (2017) conducted LCA and CBA in parallel for assessing the "environmental and cost impacts of reusing fly ash”, where a normalization factors were given to LCA and CBA results respectively for combination. On the other hand, Hoogmartens et al. (2014) identified the obstacles for combining LCA and CBA in terms of discrepancies in key focus (product vs. strategies), life span, life stages covered, metrics, and system boundaries such as whether to include impacts on broader society. These examples show that multiple ways of combining LCA with CBA exist, that can serve as the basis when integrating LCA into decision analysis in transport and flood management. But caution is needed as also discussed in above sections.

Note that in addition to the conventional environmental LCA (eLCA) as we mentioned in this study, social LCA (sLCA) and life cycle costing (LCC) also exist, though used to a less extent due to the less mature methodology. They share the same principle as the conventional LCA, but looking at social impacts and cost flows respectively. Norris et al. (2001) proposed to use LCC for accounting economical cost and discussed two approaches for combining LCA and LCC for providing sustainability decision support. Hoogmartens et al. (2014) argue that eLCA, sLCA and LCC together, the so-called life cycle sustainability assessment (LCSA), can well deliver a sustainability decision support. They imply that instead of integrating LCA into CBA, effort should be put on translating CBA into LCC for such integration. However, obstacles mentioned in the previous sections still need to be conquered, and it may face even more challenges to convince the decision makers to switch from CBA to another method as the main decision analysis tool.

An increasing trend of using LCA for sustainability assessment is observed, in addition to the combination with risk assessment, CBA and LCC as mentioned above. LCA used often for assisting eco-design of products (Bovea and Pérez-Belis, 2012). Arena et al. (2013) propose a streamlined LCA framework, where important impacts in each life stages of a car life cycle was extracted from LCA and other guidelines or standards. They are developed into a qualitative performance evaluation system to be used in the early stage decision making. Welsh-huggins and Liel (2017) did parallel risk assessment and LCA study on buildings with green roofs, where trade-offs was demonstrated between cost, material, hazard resistance and environmental impacts. As pointed out by Jeswani et al. (2010), many possibilities exist for broadening LCA in its use for a better sustainable decision support, especially in combination with other decision analysis tools such as strategic environmental 
assessment, environmental impact assessment, multi-criteria decision analysis, LCC, CBA and sLCA. However, whether a better and more systematic LCA is needed in relevant decisions largely depends on the context of study and more importantly, the stakeholders' preference. Indeed, one reason for not including comprehensive environmental assessment results in the decision analysis is stakeholders' perceptions and priorities. Although integrating LCA into decision analysis may give a better overview of potential environmental consequences that may eventually cause damages to society, these consequences are considered external in the conventional projects. As no mandatory requirements exist, most stakeholders prefer not to internalize such external costs. Another concern is the limited social acceptance when environmental impacts and their associated damages to humans and ecosystems need to be monetized or normalized to another metrics, to be able to integrate it with results from other decision analysis tools. Monetizing of non-market things using "willingness to pay" assessments assumes that individuals have the same preference in giving up or obtaining the same thing and that this willingness is not changed when facing public decision instead of private transactions (Kelman, 1981). Both assumptions are not true in reality, which may result in far-off monetary values. Putting values on human life is another issue that will always be argued on fairness and human rights (Bayles, 1978). These methodological and ethical issues may further hinder the stakeholders' willingness to include external environmental impacts into decision analysis.

Even though obstacles exist, both from methodology and stakeholders' willingness, to integrate LCA into risk assessment and CBA, the examples given above show that it may make an important difference to the decision when LCA is taken into account. The three application areas, transportation, flood management and food production and consumption, all target at decision making at societal level. Their environmental consequences will cause damage to nature and society, and disregarding them in decision analysis will eventually cause more problems to fix afterwards. Climate change is a good example of paying such prices after ignoring GHG emissions in the past. Therefore, it is highly relevant to integrate sustainability considerations into decision analysis now, e.g. using the LCAbased approaches described above to support robust decisions that avoid shifting burdens to the future.

\section{Conclusions and perspectives}

It is clear that economic benefit and cost, and impacts on human health are major concerns in decision analysis within the three research areas presented in this study. Few attempts exist to assess environmental impacts, e.g. noise and air quality assessment in transportation CBA, classification of green or grey facilities in flood management and reducing waste and harmful elements in food production and consumption. However, those methods either cover only few environmental impact categories, or act as a guideline without actually assessing the impacts. There is thus a clear need for a better assessment of environmental impacts to be incorporated into decision analysis for these research areas as well as in general in order to support sustainable system choices. As a promising tool, LCA provides a mature and ISO standardized methodology to assess a full set of environmental impacts. Previous applications in the three studied research areas have demonstrated its ability to support an informed judgement on the environmental profile of the compared alternatives. However, there are still many challenges ahead. Due to lack of common scopes and purposes, and methodological differences, the aim of study and system boundaries need to be aligned as much as 
677 practically possible between LCA and the traditional decision analysis tools, assuring the 678 compatibility in the comparison and/or aggregation of the results when possible. Similarly, 679 uncertainty and discounting are treated differently, where an alignment is needed. Moreover, metrics 680 in LCA (e.g. DALY and PDF) are different from the ones used in other decision analysis tools. 681 Although recent studies show that there are multiple ways of integrating LCA and other decision 682 support tools, further research is needed to overcome these challenges.

\section{Acknowledgement}

684 This work was supported by Global Decision Support Initiative at Technical University of Denmark. 685 We thank Peter Fantke (DTU Management) for his support as research coordinator. 


\section{References}

Andrew, R.M., Vesely, É.T., 2008. Life-cycle energy and CO2 analysis of stormwater treatment devices. Water Sci. Technol. 58, 985-993. https://doi.org/10.2166/wst.2008.455

Annema, J.A., Frenken, K., Koopmans, C., Kroesen, M., 2017. Relating cost-benefit analysis results with transport project decisions in the Netherlands. Lett. Spat. Resour. Sci. 10, 109127. https://doi.org/10.1007/s12076-016-0175-5

Arena, M., Azzone, G., Conte, A., 2013. A streamlined LCA framework to support early decision making in vehicle development. J. Clean. Prod. 41, 105-113. https://doi.org/10.1016/j.jclepro.2012.09.031

Arvanitoyannis, I.S., Kotsanopoulos, K. V., Veikou, A., 2014. Life Cycle Assessment (ISO 14040) Implementation in Foods of Animal and Plant Origin: Review. Crit. Rev. Food Sci. Nutr. 54, 1253-82. https://doi.org/10.1080/10408398.2011.631170

Åström, H., Friis Hansen, P., Garré, L., Arnbjerg-Nielsen, K., 2014. An influence diagram for urban flood risk assessment through pluvial flood hazards under non-stationary conditions. J. Water Clim. Chang. 5, 276-286. https://doi.org/10.2166/wcc.2014.103

Aven, T., 2008. Risk Analysis: Assessing Uncertainties beyond Expected Values and Probabilities. John Wiley \& Sons, Ltd, Chichester, UK. https://doi.org/10.1002/9780470694435

Barberio, G., Scalbi, S., Buttol, P., Masoni, P., Righi, S., 2014. Combining life cycle assessment and qualitative risk assessment: The case study of alumina nanofluid production. Sci. Total Environ. 496, 122-131. https://doi.org/10.1016/j.scitotenv.2014.06.135

Bare, J.C., 2006. Risk Assessment and Life-Cycle Impact Assessment (LCIA) for Human Health Cancerous and Noncancerous Emissions: Integrated and Complementary with Consistency within the USEPA. Hum. Ecol. Risk Assess. An Int. J. 12, 493-509. https://doi.org/10.1080/10807030600561683

Barjoveanu, G., Comandaru, I.M., Rodriguez-Garcia, G., Hospido, A., Teodosiu, C., 2014. Evaluation of water services system through LCA. A case study for Iasi City, Romania. Int. J. Life Cycle Assess. 19, 449-462. https://doi.org/10.1007/s11367-013-0635-8

Bayles, M.D., 1978. The Price of Life. Ethics 89, 20-34.

Bedford, T., Cooke, R., 2001. Probabilistic Risk Analysis, Foundations and Methods. Cambridge University Press, New York. https://doi.org/10.1198/016214502760301264

Belmeziti, A., Cherqui, F., Tourne, A., Granger, D., Werey, C., Le Gauffre, P., Chocat, B., 2015. Transitioning to sustainable urban water management systems: how to define expected service functions? Civ. Eng. Environ. Syst. 32, 316-334. https://doi.org/10.1080/10286608.2015.1047355

Benetto, E., Tiruta-barna, L., Perrodin, Y., 2007. Combining lifecycle and risk assessments of mineral waste reuse scenarios for decision making support 27, 266-285. https://doi.org/10.1016/j.eiar.2006.10.007

Bjørn, A., Hauschild, M.Z., 2015. Introducing carrying capacity-based normalisation in LCA: 
framework and development of references at midpoint level. Int. J. Life Cycle Assess. 20, 1005-1018. https://doi.org/10.1007/s11367-015-0899-2

Bohnes, F.A., Gregg, J.S., Laurent, A., 2017. Environmental Impacts of Future Urban Deployment of Electric Vehicles: Assessment Framework and Case Study of Copenhagen for 2016-2030. Environ. Sci. Technol. 51, 13995-14005. https://doi.org/10.1021/acs.est.7b01780

Bosso, C., Isaacs, J., Walker, W., 2012. Life cycle assessment in regulatory decision-making, in: IEEE International Symposium on Sustainable Systems and Technology. Boston, U.S.A. https://doi.org/10.1109/ISSST.2012.6228024

Bovea, M.D., Pérez-Belis, V., 2012. A taxonomy of ecodesign tools for integrating environmental requirements into the product design process. J. Clean. Prod. 20, 61-71. https://doi.org/10.1016/j.jclepro.2011.07.012

Brudler, S., Arnbjerg-nielsen, K., Hauschild, M., Rygaard, M., 2016. Life cycle assessment of stormwater management in the context of climate change adaptation. Water Res. 106, 394404. https://doi.org/10.1016/j.watres.2016.10.024

Chester, M. V., Horvath, A., Madanat, S., 2010. Comparison of life-cycle energy and emissions footprints of passenger transportation in metropolitan regions. Atmos. Environ. 44, 10711079. https://doi.org/10.1016/j.atmosenv.2009.12.012

Chester, M. V, Horvath, A., 2009. Environmental assessment of passenger transportation should include infrastructure and supply chains. Environ. Res. Lett. 4, 024008. https://doi.org/10.1088/1748-9326/4/2/024008

Cowell, S.J., Fairman, R., Lofstedt, R.E., 2002. Use of risk assessment and life cycle assessment in decision making: a common policy research agenda. Risk Anal. 22, 879-894.

Danish Ministry of Transport, 2015. Manual for samfundsøkonomisk analyse på transportområdet. Guidance Document prepared for the Danish Ministry of Transport (DMT). Copenhagen, Denmark.

de Jong, G., Daly, A., Pieters, M., Miller, S., Plasmeijer, R., Hofman, F., 2007. Uncertainty in traffic forecasts: Literature review and new results for The Netherlands. Transportation (Amst). 34, 375-395. https://doi.org/10.1007/s11116-006-9110-8

De Sousa, M.R.C., Montalto, F.A., Spatari, S., 2012. Using Life Cycle Assessment to Evaluate Green and Grey Combined Sewer Overflow Control Strategies. J. Ind. Ecol. 16, 901-913. https://doi.org/10.1111/j.1530-9290.2012.00534.x

Dhingra, R., Naidu, S., Upreti, G., Sawhney, R., 2010. Sustainable nanotechnology: Through green methods and life-cycle thinking. Sustainability 2, 3323-3338. https://doi.org/10.3390/su2103323

EC-JRC, 2010. ILCD handbook: General guide for Life Cycle Assessment-- Detailed guidance. https://doi.org/10.2788/38479

Eddington, S.R., 2006. The Eddington Transport Study: Main report: Transport's role in sustaining the UK’s productivity and competitiveness. HM Treasury. 
EFSA, 2006. Risk-benefit analysis of foods: methods and approaches. EFSA scientific colloquium summary report number 6 . Parma, Italy.

EIB, 2013. The Economic Appraisal of Investment Projects at the European Investment Bank.

Engelbrecht, H.J., 2009. Natural capital, subjective well-being, and the new welfare economics of sustainability: Some evidence from cross-country regressions. Ecol. Econ. 69, 380-388. https://doi.org/10.1016/j.ecolecon.2009.08.011

Ercan, T., Zhao, Y., Tatari, O., Pazour, J.A., 2015. Optimization of transit bus fleet’s life cycle assessment impacts with alternative fuel options. Energy 93, 323-334. https://doi.org/10.1016/j.energy.2015.09.018

EU, 2006. Regulation (EC) No 1907/2006 of the European parliament and of the council of 18 December 2006.

European Commission, 2016. European platform on Life Cycle Assessment (LCA) [WWW Document]. URL http://ec.europa.eu/environment/ipp/lca.htm

European Commission, 2014. Guide to Cost-benefit Analysis of Investment Projects Economic appraisal tool for Cohesion Policy 2014-2020. European Union. https://doi.org/10.2776/97516

European Commission, 2007. Directive 2007/60/EC of the European Parliament and of the Council of 23 October 2007 on the assessment and management of flood risks.

European Commission, 2002. REGULATION (EC) No 178/2002 OF THE EUROPEAN PARLIAMENT AND OF THE COUNCIL of 28 January 2002: laying down the general principles and requirements of food law, establishing the European Food Safety Authority and laying down procedures in matters of food sa.

European Union, 2012. Seveso III Directive: DIRECTIVE 2012/18/EU OF THE EUROPEAN PARLIAMENT AND OF THE COUNCIL of 4 July 2012 on the control of major-accident hazards involving dangerous substances, amending and subsequently repealing Council Directive 96/82/EC. Off. J. Eur. Union 1-37. https://doi.org/doi:10.3000/19770677.L_2013.124.eng

Faber, M.H., 2012. Statistics and Probability Theory: In Pursuit of Engineering Decision Support. Springer, Kgs. Lyngby, Denmark. https://doi.org/10.1007/978-94-007-4056-3

Fagnant, D., Kockelman, K., 2012. Outcome of transportation projects under uncertainty: examination of Benefit-Cost Ratios and other impacts. Transp. Res. Rec. 89-98. https://doi.org/10.3141/2303-10

FAO, WHO, 2005. Food Safety Risk Analysis Part I: An Overview and Framework Manual. Rome, Italy.

Figueira, J., Greco, S., Ehrgott, M., 2005. Multiple Criteria Decision Analysis: State of the Art Surveys, Methods. Springer. https://doi.org/10.1007/b100605

Flemström, K., Carlson, R., Erixon, M., 2004. Relationships between life cycle assessment and risk assessment -Potentials and Obstacles. Stockholm, Sweden. 
Flynn, K.M., Traver, R.G., 2013. Green infrastructure life cycle assessment: A bio-infiltration case study. Ecol. Eng. 55, 9-22. https://doi.org/10.1016/j.ecoleng.2013.01.004

Freibauer, A., Mathijs, E., Brunori, G., Damianova, Z., Faroult, E., Gomis, J.G. i, O’Brien, L., Treyer, S., 2011. Sustainable food consumption and production in a resource-constrained world. https://doi.org/10.2777/49719

French, S., Rios Insua, D., 2000. Statistical Decision Theory: Kendall’s Library of Statistics 9. Wiley\&Sons.

Funtowicz, S.O., Ravertz, J.R., 1990. Uncertainty and Quality in Science for Policy. Kluwer Academic Publishers, Dordrecht, Netherland. https://doi.org/10.1017/CBO9781107415324.004

Garcia, R., Freire, F., 2017. A review of fleet-based life-cycle approaches focusing on energy and environmental impacts of vehicles. Renew. Sustain. Energy Rev. 79, 935-945. https://doi.org/10.1016/j.rser.2017.05.145

Gibbons, S., Overman, H., 2009. Productivity in transport evaluation studies.

Goldstein, B., Birkved, M., Quitzau, M.-B., Hauschild, M., 2013. Quantification of urban metabolism through coupling with the life cycle assessment framework: concept development and case study. Environ. Res. Lett. 8, 035024. https://doi.org/10.1088/1748-9326/8/3/035024

Guinée, J.B., Heijungs, R., Vijver, M.G., Peijnenburg, W.J.G.M., 2017. Setting the stage for debating the roles of risk assessment and life-cycle assessment of engineered nanomaterials. Nat. Nanotechnol. 12, 727-733. https://doi.org/10.1038/nnano.2017.135

Halsnæs, K., Kaspersen, P.S., Drews, M., 2015. Key drivers and economic consequences of highend climate scenarios: Uncertainties and risks. Clim. Res. 64, 85-98. https://doi.org/10.3354/cr01308

Hammervold, J., Reenaas, M., Brattebø, H., 2013. Environmental Life Cycle Assessment of Bridges. Bridg. Eng. 18, 153-161. https://doi.org/10.1061/(ASCE)BE.1943-5592.0000328.

Harder, R., Holmquist, H., Molander, S., Svanström, M., Peters, G.M., 2015. Review of Environmental Assessment Case Studies Blending Elements of Risk Assessment and Life Cycle Assessment. Environ. Sci. Technol. 49, 13083-13093. https://doi.org/10.1021/acs.est.5b03302

Hauschild, M., 2005. Assessing environmental impacts in a life-cycle perspective. Environ. Sci. Technol. 39.

Hauschild, M.Z., Goedkoop, M., Guinée, J., Heijungs, R., Huijbregts, M., Jolliet, O., Margni, M., De Schryver, A., Humbert, S., Laurent, A., Sala, S., Pant, R., 2013. Identifying best existing practice for characterization modeling in life cycle impact assessment. Int. J. Life Cycle Assess. 18, 683-697. https://doi.org/10.1007/s11367-012-0489-5

Heijungs, R., Frischknecht, R., 2005. Representing statistical distributions for uncertain parameters in LCA. Int. J. Life Cycle Assess. 10, 248-254. https://doi.org/http://dx.doi.org/10.1065/lca2004.09.177 
Hellweg, S., 2003. Discounting and the environment - Should current impacts be weighted differently than impacts harming future generations? Int. J. Life Cycle Assess. 8, 8-18. https://doi.org/10.1065/lca2002.09.097

Hoogmartens, R., Van Passel, S., Van Acker, K., Dubois, M., 2014. Bridging the gap between LCA, LCC and CBA as sustainability assessment tools. Environ. Impact Assess. Rev. 48, 2733. https://doi.org/10.1016/j.eiar.2014.05.001

Huang, T.Y., Chiueh, P.T., Lo, S.L., 2017. Life-cycle environmental and cost impacts of reusing fly ash. Resour. Conserv. Recycl. 123, 255-260. https://doi.org/10.1016/j.resconrec.2016.07.001

Huijbregts, M.A.J., Verones, F., Azevedo, L.B., Chaudhary, A., Cosme, N., Fantke, P., Goedkoop, M., Hauschild, M., Laurent, A., Mutel, C.L., Pfister, S., Ponsioen, T., Steinmann, Z., van Zelm, R., Vielra, M., Hellweg, S., 2015. LC-Impact report version 0.1.

JCSS, 2008. Risk Assessment in Engineering Principles , System Representation \& Risk Criteria Joint Committee on Structural Safety.

Jeswani, H.K., Azapagic, A., Schepelmann, P., Ritthoff, M., 2010. Options for broadening and deepening the LCA approaches. J. Clean. Prod. 18, 120-127. https://doi.org/10.1016/j.jclepro.2009.09.023

Jones, H.L., Moura, F., Domingos, T., 2017. Transportation Infrastructure Project Evaluation : Transforming CBA to Include a Life Cycle Perspective. Handb. Sustain. Sci. Res. 745-771. https://doi.org/10.1007/978-3-319-63007-6_46

Kahn, M.E., 2007. Environmental disasters as risk regulation catalysts? The role of Bhopal, Chernobyl, Exxon Valdez, Love Canal, and Three Mile Island in shaping U.S. environmental law. J. Risk Uncertain. 35, 17-43. https://doi.org/10.1007/s11166-007-9016-7

Keeney, R.L., 1982. Decision analysis: an overview. Oper. Res. 30, 803-838.

Keeney, R.L., Raiffa, H., 1993. Decisions With Multiple Objectives-Preferences and Value Tradeoffs. Cambridge University Press, Cambridge \& New York.

Kelman, S., 1981. Cost-Benefit Analysis An Ethical Critique. Regulation 33-40.

Kimball, M., Chester, M., Gino, C., Reyna, J., 2013. Assessing the Potential for Reducing LifeCycle Environmental Impacts through Transit-Oriented Development Infill along Existing Light Rail in Phoenix. J. Plan. Educ. Res. 33, 395-410. https://doi.org/10.1177/0739456X13507485

Kiureghian, A. Der, Ditlevsen, O., 2009. Aleatory or epistemic? Does it matter? Struct. Saf. 31, 105-112. https://doi.org/10.1016/j.strusafe.2008.06.020

Kloepffer, W., 2008. Life cycle sustainability assessment of products. Int. J. Life Cycle Assess. 13, 89-95.

Klüppelberg, C., Straub, D., Welpe, I.., 2014. Risk-A Multidisciplinary introduction. https://doi.org/10.1007/978-3-319-04486-6

Lai, E., Lundie, S., Ashbolt, N.J., 2008. Review of multi-criteria decision aid for integrated 
sustainability assessment of urban water systems. Urban Water J. 5, 315-327. https://doi.org/10.1080/15730620802041038

Levasseur, A., Lesage, P., Margni, M., Deschênes, L., Samson, R., 2010. Considering time in LCA: dynamic LCA and its application to global warming impact assessments. Environ. Sci. Technol. 44, 3169-74. https://doi.org/10.1021/es9030003

Linkov, I., Seager, T.P., 2011. Coupling Multi-Criteria Decision Analysis, Life-Cycle Assessment, and Risk Assessment for Emerging Threats 5068-5074. https://doi.org/10.1021/es100959q

Linkov, I., Trump, B.D., Wender, B.A., Seager, T.P., Kennedy, A.J., Keisler, J.M., 2017. Integrate life-cycle assessment and risk analysis results, not methods. Nat. Nanotechnol. 12, 740-743. https://doi.org/10.1038/nnano.2017.152

Linneberg, P., Puddicombe, R., Castlo, D., 2014. Life-cycle assessment tool for railway infrastructure. Bridg. Maintenance, Safety, Manag. Life Ext. 1064-1068.

Lloyd, S.M., Ries, R., 2007. Characterizing, propagating, and analyzing uncertainty in Life-Cycle Assessment: A survey of quantitative approaches. J. Ind. Ecol. 11, 161-181. https://doi.org/10.1162/jiec.2007.1136

Loiseau, E., Aissani, L., Le Féon, S., Laurent, F., Cerceau, J., Sala, S., Roux, P., 2018. Territorial Life Cycle Assessment (LCA): What exactly is it about? A proposal towards using a common terminology and a research agenda. J. Clean. Prod. 176, 474-485. https://doi.org/10.1016/j.jclepro.2017.12.169

Lombardi, L., Tribioli, L., Cozzolino, R., Bella, G., 2017. Comparative environmental assessment of conventional, electric, hybrid, and fuel cell powertrains based on LCA. Int. J. Life Cycle Assess. 22, 1989-2006. https://doi.org/10.1007/s11367-017-1294-y

Lotteau, M., Loubet, P., Pousse, M., Dufrasnes, E., Sonnemann, G., 2015. Critical review of life cycle assessment (LCA) for the built environment at the neighborhood scale. Build. Environ. 93, 165-178. https://doi.org/10.1016/j.buildenv.2015.06.029

Manzo, S., Salling, K.B., 2016. Integrating Life-cycle Assessment into Transport Cost-benefit Analysis, in: Transportation Research Procedia. pp. 273-282. https://doi.org/10.1016/j.trpro.2016.05.064

Martin, C., Ruperd, Y., Legret, M., 2007. Urban stormwater drainage management: The development of a multicriteria decision aid approach for best management practices. Eur. J. Oper. Res. 181, 338-349. https://doi.org/10.1016/j.ejor.2006.06.019

Merz, B., Aerts, J., Arnbjerg-Nielsen, K., Baldi, M., Becker, A., Bichet, A., Blöschl, G., Bouwer, L.M., Brauer, A., Cioffi, F., Delgado, J.M., Gocht, M., Guzzetti, F., Harrigan, S., Hirschboeck, K., Kilsby, C., Kron, W., Kwon, H.H., Lall, U., Merz, R., Nissen, K., Salvatti, P., Swierczynski, T., Ulbrich, U., Viglione, A., Ward, P.J., Weiler, M., Wilhelm, B., Nied, M., 2014. Floods and climate: emerging perspectives for flood risk assessment and management. Nat. Hazards Earth Syst. Sci. 14, 1921-1942. https://doi.org/10.5194/nhess-14-1921-2014

Meyer, V., Becker, N., Markantonis, V., Schwarze, R., Van Den Bergh, J.C.J.M., Bouwer, L.M., Bubeck, P., Ciavola, P., Genovese, E., Green, C., Hallegatte, S., Kreibich, H., Lequeux, Q., 
Logar, I., Papyrakis, E., Pfurtscheller, C., Poussin, J., Przyluski, V., Thieken, A.H., Viavattene, C., 2013. Review article: Assessing the costs of natural hazards-state of the art and knowledge gaps. Nat. Hazards Earth Syst. Sci. 13, 1351-1373. https://doi.org/10.5194/nhess-13-13512013

Mishan, E.J., Quah, E., 2007. Cost-Benefit Analysis, fifth edit. ed. Routledge.

Møller, F., Slentø, E., Frederiksen, P., 2013. Integrated well-to-wheel assessment of biofuels combining energy and emission LCA and welfare economic Cost Benefit Analysis. Biomass and Bioenergy 60, 41-49. https://doi.org/10.1016/j.biombioe.2013.11.001

Motarjemi, Y., Moy, G., Todd, E., 2014. Encyclopedia of Food Safety. Elsevier.

Munda, G., 2005. Multiple criteria decision analysis and sustainable development. Int. Ser. Oper. Res. Manag. Sci. https://doi.org/10.1007/0-387-23081-5_23

Norris, G.A., 2001. Integrating Life Cycle Cost Analysis and LCA. Int. J. Life Cycle Assess. 6, $118-120$.

OECD, 2015. Guidance manual towards the integration of risk assessment into life cycle assessment of nano-enabled applications.

Olsen, S.I., Christensen, F.M., Hauschild, M., Pedersen, F., Larsen, H.F., Tørsløv, J., 2001. Life cycle impact assessment and risk assessment of chemicals - A methodological comparison. Environ. Impact Assess. Rev. 21, 385-404. https://doi.org/10.1016/S0195-9255(01)00075-0

Raiffa, H., Schlaifer, R., 1961. Applied Statistical Decision Theory. Harvard Press.

Rasouli, S., Timmermans, H., 2012. Uncertainty in travel demand forecasting models: literature review and research agenda. Transp. Lett. Int. J. Transp. Res. 4, 55-73. https://doi.org/10.3328/TL.2012.04.01.55-73

Ribera, G., Clarens, F., Martínez-Lladó, X., Jubany, I., V.Martí, Rovira, M., 2014. Life cycle and human health risk assessments as tools for decision making in the design and implementation of nanofiltration in drinking water treatment plants. Sci. Total Environ. 466-467, 377-386. https://doi.org/10.1016/j.scitotenv.2013.06.085

Roy, P., Nei, D., Orikasa, T., Xu, Q., Okadome, H., Nakamura, N., Shiina, T., 2009. A review of life cycle assessment (LCA) on some food products. J. Food Eng. 90, 1-10. https://doi.org/10.1016/j.jfoodeng.2008.06.016

Sala, S., Farioli, F., Zamagni, A., 2013. Progress in sustainability science: Lessons learnt from current methodologies for sustainability assessment: Part 1. Int. J. Life Cycle Assess. 18, 1653-1672. https://doi.org/10.1007/s11367-012-0508-6

Salling, K.B., Leleur, S., 2015. Accounting for the inaccuracies in demand forecasts and construction cost estimations in transport project evaluation. Transp. Policy 38, 8-18. https://doi.org/10.1016/j.tranpol.2014.11.006

Sen, B., Ercan, T., Tatari, O., 2017. Does a battery-electric truck make a difference? - Life cycle emissions, costs, and externality analysis of alternative fuel-powered Class 8 heavy-duty trucks in the United States. J. Clean. Prod. 141, 110-121. 
953

954

955

956

957

958

959

960

961

962

963

964

965

966

967

968

969

970

971

972

973

974

975

976

977

978

979

980

981

982

983

984

985

986

987

988

989

Spatari, S., Yu, Z., Montalto, F.A., 2011. Life cycle implications of urban green infrastructure. Environ. Pollut. 159, 2174-2179. https://doi.org/10.1016/j.envpol.2011.01.015

Stylianou, K.S., Heller, M.C., Fulgoni, V.L., Ernstoff, A.S., Keoleian, G.A., Jolliet, O., 2016. A life cycle assessment framework combining nutritional and environmental health impacts of diet: a case study on milk. Int. J. Life Cycle Assess. 21, 734-746. https://doi.org/10.1007/s11367015-0961-0

Tsang, M.P., Bates, M.E., Madison, M., Linkov, I., 2014. Bene fits and Risks of Emerging Technologies : Integrating Life Cycle Assessment and Decision Analysis To Assess Lumber Treatment Alternatives. https://doi.org/10.1021/es501996s

UNEP, 2014. Sustainable Consumption and Production (SCP) targets and indicators and the SDGs.

van der Goot, A.J., Pelgrom, P.J.M., Berghout, J.A.M., Geerts, M.E.J., Jankowiak, L., Hardt, N.A., Keijer, J., Schutyser, M.A.I., Nikiforidis, C. V, Boom, R.M., 2016. Concepts for further sustainable production of foods. J. Food Eng. 168, 42-51. https://doi.org/http://dx.doi.org/10.1016/j.jfoodeng.2015.07.010

van Zelm, R., Huijbregts, M., 2013. Quantifying the trade-off between parameter and model structure uncertainty in life cycle impact assessment. Environ. Sci. Technol. 47, 9274-80. https://doi.org/10.1021/es305107s

Vose, D.J., 1998. The application of quantitative risk assessment to microbial food safety. J. Food Prot. 61, 640-648.

Walker, W.E., Harremoëes, P., Rotmans, J.P., van der Sluijs, J.P., van Asselt, M.B.A., Janssen, P., Krayer Von Krauss, M.P., 2003. Defining uncertainty: a conceptual basis for uncertainty management. Integr. Assess. 4, 5-17. https://doi.org/10.1076/iaij.4.1.5.16466

Welsh-huggins, S.J., Liel, A.B., 2017. A life-cycle framework for integrating green building and hazard-resistant design : examining the seismic impacts of buildings with green roofs examining the seismic impacts of buildings with green roofs. Struct. Infrastruct. Eng. 2479, 115. https://doi.org/10.1080/15732479.2016.1198396

Wernet, G., Bauer, C., Steubing, B., Reinhard, J., Moreno-Ruiz, E., Weidema, B., 2016. The ecoinvent database version 3 (part I): overview and methodology. Int. J. Life Cycle Assess. 21, 1218-1230. https://doi.org/10.1007/s11367-016-1087-8

WHO, 1995. Application of risk analysis to food standards issues. Geneva, Switzland.

Zhou, Q., Mikkelsen, P.S., Halsnæs, K., Arnbjerg-Nielsen, K., 2012. Framework for economic pluvial flood risk assessment considering climate change effects and adaptation benefits. J. Hydrol. 414-415, 539-549. https://doi.org/10.1016/j.jhydrol.2011.11.031

Zijp, M.C., Waaijers-van der Loop, S.L., Heijungs, R., Broeren, M.L.M., Peeters, R., Van Nieuwenhuijzen, A., Shen, L., Heugens, E.H.W., Posthuma, L., 2017. Method selection for sustainability assessments: The case of recovery of resources from waste water. J. Environ. Manage. 197, 221-230. https://doi.org/10.1016/j.jenvman.2017.04.006 
990 


\section{Vitae}

992 Yan Dong is a Postdoc at quantitative assessment of sustainability in the Technical University of 993 Denmark. She has worked on methodology development of life cycle assessment (LCA) during her 994 Ph.D. Her current research focus is to apply quantitative sustainability assessment in decision making. 995 This includes developing harmonized metrics between sustainability assessment approaches and 996 other decision making tools, monetizing environmental impacts, and improving uncertainty treatment 997 in LCA.

Simona Miraglia is an assistant professor at Aalborg University within the division of Reliability, Dynamics and Marine Engineering at the Civil Engineering Department. Her background is in computational mechanics, uncertainty quantification for structural reliability and risk analysis for infrastructure systems management and she has been working in applied research and consultancy for the public sector. Her research focus is on statistical decision theory, system resilience modelling and integration of sustainability and risk for decision support and policy making.

1005

1006

Stefano Manzo is a Postdoc at the Technical University of Denmark within the domains of Transport modelling and project evaluation. His current research area is on combining quantitative sustainability and model uncertainty assessment methods with standard transport projects evaluation frameworks. The overall aim is to provide decision takers with more sustainability oriented tools, including the information about the uncertainty related to the different framework components.

Stylianos Georgiadis is a Postdoctoral fellow in Applied Mathematics at Technical University of Denmark within statistics and data Analysis. His research interests include uncertainty quantification in risk management, life cycle assessment and decision analysis; and stochastic and statistical modelling with application in urban water systems, food risk assessment, structures, reliability and queueing models.

Hjalte Jomo Danielsen Sørup is an assistant professor at the Technical University of Denmark within Urban Water Systems Modelling. His main research area is on combining risk and quantitative sustainability assessments for flood risk assessment to develop decision support tools that help decision makers take more sustainable decisions in the light of the associated risks and uncertainties. He has also been working intensively with input uncertainty for such models, especially on rainfall in a changed climate. 
1025 Elena Boriani is Postdoc at the Technical University of Denmark within GDSI and National Food Institute, Department Research Group for Genomic Epidemiology. Elena has been working with in silico methodologies to assess chemical compounds toxicity and physical chemical properties and she is now applying these methodologies to food case studies. Her research interests are also in the field of public health using system thinking analysis to overview transdisciplinary projects.

1030

1031

1032

1033

1034

1035

1036

1037

1038

1039

1040

1041

1042

1043

1044

1045

1046

1047

1048

1049

1050

1051

1052

1053

1054

1055

1056

1057

1058

1059
Tine Hald is a professor in translational epidemiology, at national food institute in Technical university of Denmark. Her work focuses on research and development of mathematical models for explaining the transmission and assessing the burden of zoonoses and foodborne diseases, including methods for identifying and prioritizing interventions. Tine has been pioneering the international development and application of methods for source attribution of foodborne diseases. Tine is a core member of the World Health Organisations' (WHO) Foodborne disease Epidemiology Reference Group (FERG) and from 2009-2015, she was a member of the European Food Safety Authority (EFSA) expert panel on biological hazards (BIOHAZ).

Sebastian Thöns is heading the research group of Engineering Risk and Decision Analysis (ERDA) at Technical University of Denmark (DTU) associated to the Department of Civil Engineering. His work is focussed on Value of Information analyses working on progressing fundamental research and engineering applications. He is active in several European projects and interdisciplinary research and networking projects. He acts as an Academic Board Member of the Global Decision Support Initiative (GDSI) and a Scientific Advisor of the Danish Hydrocarbon Research and Technology Centre (DHRTC). Since 2015 he chairs the COST Action TU1402 on Quantifying the Value of Structural Health Monitoring.

Michael Z. Hauschild is professor in quantitative assessment of sustainability at the Technical University of Denmark (DTU) and has worked on the development of methods for sustainability assessment of products and technologies for more than 20 years. He has an extensive experience in the development of metrics and indicators for sustainability, and served as chair on consecutive working groups under UNEP-SETAC Life Cycle Initiative developing the recommended scientific consensus model USEtox (www.usetox.org) for assessment of chemical impacts on health and environment. He leads the division on Quantitative Sustainability Assessment at Management Engineering Department of DTU. 